Sharif University of Technology
Scientia Iranica

\title{
Multi-class appliance scheduling for cost-effective energy management with constraint and user preferences
}

\author{
M.F. Ali Khan* and P.V. Chandramani \\ Department of Electronics and Communication Engineering, Sri Sivasubramaniya Nadar College of Engineering, Tamilnadu, India.
}

Received 3 October 2019; received in revised form 9 November 2020; accepted 4 January 2021

\author{
KEYWORDS \\ Artificial Neural \\ Network (ANN); \\ Home energy \\ management; \\ Multi-class appliance; \\ Net-meter; \\ Pattern-generation \\ algorithm; \\ User comfort.
}

\begin{abstract}
It took decades for electrical power grids to transform from traditional to smart power grids with focus on transparency on utility and consumer. Energy management systems play a substantial role in responding to demands within the smart power grid umbrella, enabling demand-side management at the residential level. These systems generate consumption profiles of appliances and reduce the burden on end-user in scheduling appliance operations. By using these consumption profiles of past usage, there is a possibility to generate a time window containing user preferable time slots for appliance operation for the next day. Using this time window, one can generate a cost-effective schedule pattern autonomously. In this regard, this paper proposes a home energy-demand management scheme consisting of a time window generator and a schedule pattern generator to generate a cost-effective comfortable scheduling pattern with a demand threshold constraint. Multi-class home appliances enabled with a net-meter indicate the effectiveness of the proposed approach. The simulation results illustrate that the proposed approach helps users save electricity bills with constraint preserving comfort.
\end{abstract}

(C) 2022 Sharif University of Technology. All rights reserved.

\section{Introduction}

Energy Management Systems (EMSs) appear to be viable and suitable from the grid and consumer perspectives. EMSs on the grid side target efficient generation, transmission, and distribution and aim at cost-effective planning, monitoring, and scheduling energy needs on the consumer side [1]. The demand side, mostly the residential area, consumes a substantial portion of the power generated compared to commercial and indus-

\footnotetext{
*. Corresponding author. Tel.: +919849098630 E-mail address: mfirdousealikhan@gmail.com (M.F.Ali Khan)
}

doi: $10.24200 /$ sci. 2021.54570 .3812 trial sectors [2]. A smart power grid combined with demand response enables demand-side management in residential areas to make a balance between the grid supply and consumer demand [3]. This balance avoids blackouts and brownouts during peak hours and also avoids underutilization of power during off-peak hours. The demand response in residential areas makes demand management possible not only at the grid level via direct load control mechanism (in real time) but also at the residence level via appliance scheduling (day ahead ) [4-6]. This appliance scheduling provides enduser/consumers with an opportunity to cost-effectively operate appliances under a dynamic pricing scheme via Home Energy Management (HEM) systems. The costeffective operation of appliances allows individuals to reduce Electricity Bill (EB) with full or no comfort by 
shifting the operation of appliances through scheduling algorithms [7-10].

Scheduling of appliance operations via algorithms has drawn significant attention in recent years, enabling end-users to control appliances concerning timevarying electricity tariffs. The scheduling algorithms incorporate utility updates (day-ahead electricity tariff) with rooftop photovoltaic (PV) information and end-user preferences to plan home appliance operations [11-13]. Numerous models and algorithms for appliance scheduling, including variable tariffs and thresholds on power, derived from the grid with different pricing schemes or demand management approaches addressing either EB reduction or uncompromised user's comfort are observed in the literature as discussed below.

Loenthiran et al. [9] proposed appliances scheduling using load shifting techniques to reduce EB. Such demand shifting techniques may discomfort the user due to operational delays. In [10], researchers presented a mathematically developed model to schedule appliances using a linear programming technique for EB reduction. In [11], a heating-ventilation-air-conditioning model was presented for the HEM system using mixedinteger nonlinear programming to reduce EB. However, the model considers only EB minimization. In [12], the authors presented linear programming models for appliance scheduling to minimize EB. In [13], an HEM system compromising user comfort was designed for EB reduction via appliance scheduling. In [14], the authors defined the objectives and constraint functions mathematically to reduce EB. However, the function considers only EB minimization as an objective. In [15], the authors presented a scheduling algorithm to control operational time and energy consumption of appliances using mixed-integer nonlinear programming for reducing EB. The authors in [9-15] did not consider demand peaks and operational delays that might arise due to shifting demand at off-peak hours or during lowtariff hours while reducing EB.

In [16], the HEM algorithm using a mathematical model of home appliances was proposed to minimize user discomfort and EB. In [17], a mathematical model of optimization using mixed-integer nonlinear programming and heuristic algorithms was suggested to minimize EB and discomfort. In [18], the authors presented a mathematical formulation of the objective function and algorithm for EB reduction with comfort, considering the limited number of appliances. In [19], researchers adopted a flexible load control strategy to schedule appliances for reducing EB and discomfort. Ma et al. [20] proposed appliance scheduling under day-ahead pricing using integer linear programming to reduce EB comfort. In [21], a decentralized HEM framework was given to minimize EB while preserving user preferences. In [22], appliance scheduling using demand shifting techniques for HEM including renewable energy sources was proposed to reduce energy consumption, thereby decreasing EB with user comfort. In [23], the authors adopted a bottom-up approach to HEM using smart plugs to reduce EB and maintain user comfort. The authors in [16-23] did not consider demand peaks that might be developed during EB reduction while preserving user comfort.

Following a review of the literature, it becomes clear that the reported HEM schemes generate a dayahead schedule pattern for appliances to reduce EB by shifting appliance operation to a non-preferable hour, thereby compromising the end-user comfort. Some HEM schemes entirely prefer addressing user comfort alone. In both cases, the schemes do not consider demand peaks that may occur while reducing EB with user comfort. Thus, our observation shows that this field needs immediate addressing to achieve costeffective energy management with user comfort and demand threshold constraints via scheduling of appliance operations. However, if past consumption profiles of appliance operations are available, a time window containing user-preferred time slots for an appliance operation can be generated. The user or utility can set a demand threshold or grid power draw constraint to maintain a demand below a certain level, thereby suppressing demand peaks without curtailing. If costeffective scheduling patterns are generated from these windows autonomously considering constraints, then cost-effective energy management with user comfort and constraint is possible. Therefore, this paper proposes an HEM scheme consisting of a time window generator, a schedule-pattern generator, a demand threshold, and a grid power draw constraint to generate a cost-effectively comfortable schedule pattern.

A home with multi-class appliances enabled with a net-meter and demand threshold constraint demonstrates the effectiveness of the proposed approach. The simulation results showcase the performance of the proposed approach compared to the outcome of fullcomfort schedule-pattern and cost-effective comfortable schedule pattern, thereby achieving EB saving with comfort and constraint. In the rest of the article, Section 2 presents an overview of the HEM system model. Section 3 formulates and defines both time window and schedule-pattern generation algorithms. Section 4 shows simulation results. Section 5 concludes the paper with the benefits of the proposed algorithms to the user.

\section{Home Energy Management (HEM) model}

This section presents an HEM scheme for a net-meterenabled home with entities like multi-class appliances demand, grid-tied rooftop PV power information, dayahead electricity tariff on the utility, grid power con- 


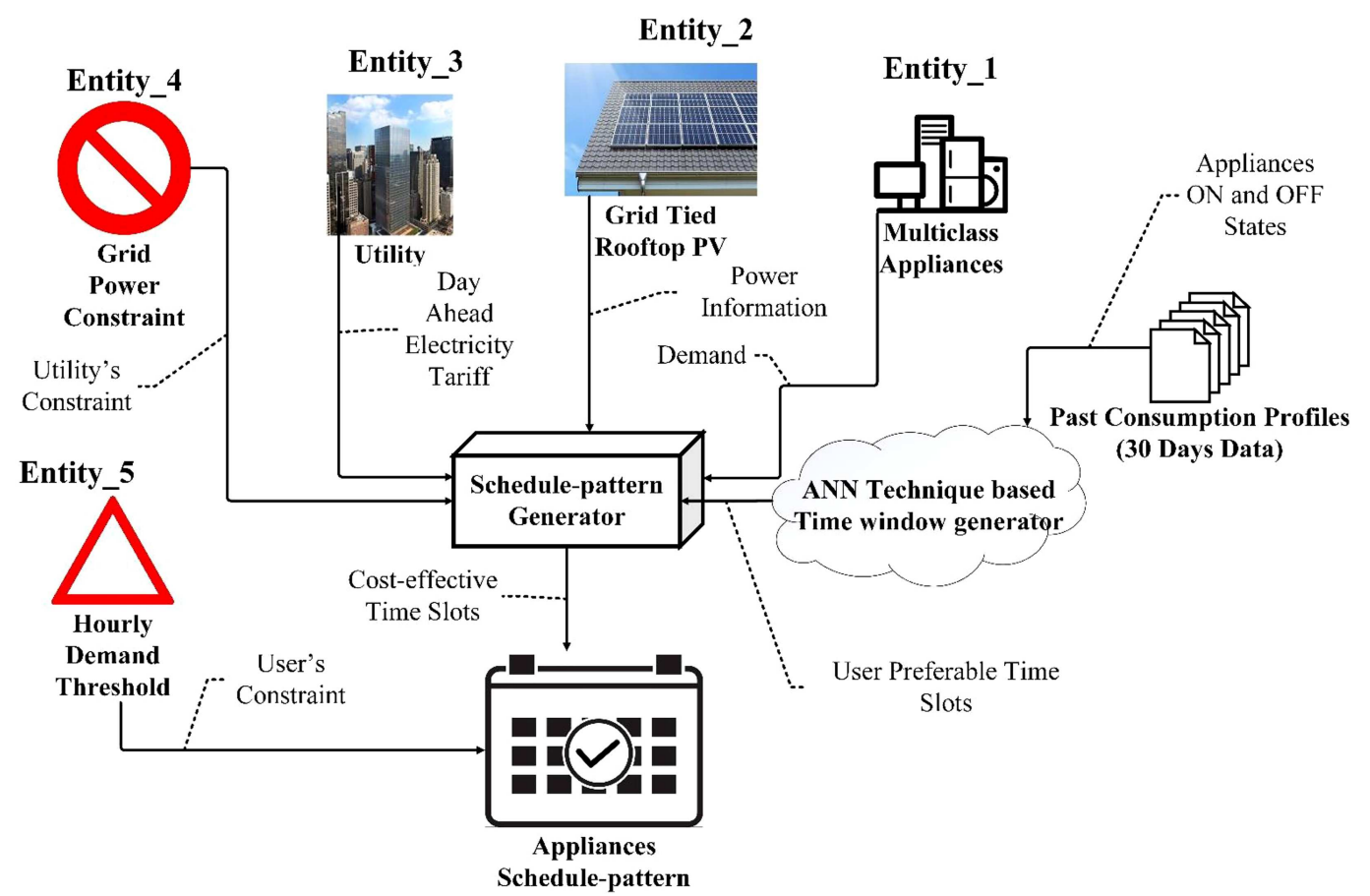

Figure 1. Household energy management model.

straint, and hourly demand threshold constraint, as shown in Figure 1.

\section{Entity_1-multi-class appliances demand}

From the literature review, we have predominantly observed that the reported HEM schemes consider two types of load, shiftable and non-shiftable, to generate a day-ahead scheduling pattern for appliance operation. Some HEM schemes also assume interruptible and noninterruptible appliances for scheduling in real time. Our approach functions in line with those existing in the literature, which generates a schedule pattern dayahead of appliance operation. Therefore, this paper considers a set of multi-class appliances $A$ classified into two broad categories based on their demand-type shiftable and non-shiftable as Class $s_{N A}$ and Class $_{S A}$, respectively, as shown in Eq. (1):

$$
A=\left\{\text { Class }_{N A} \cup \text { Class }_{S A}\right\} .
$$

These appliances are operated at their defined time slots or at an appropriate time slot based on their type. Class $_{S A}$ appliances get operated at an appropriate time slot of the day, whereas Class $_{N A}$ appliances get operated at user-defined time slots. However, some shiftable appliances get operated one time in a day (such as kettle, iron, water heater, vacuum cleaner, and well pump), two times a day (such as rice cooker and electric stove), and one time for two continuous hours in a day (such as washing machine).

Therefore, Class $_{S A}$ appliances are categorized further into three types as Class $s_{S O}$, Class $_{S T}$, and Class ${ }_{S C}$ based on their possibility of being operated once, twice, and once for two continuous hours a day, respectively, as indicated in Eq. (2):

$$
\text { Class }_{S A}=\left\{\text { Class }_{S O} \cup \text { Class }_{S T} \cup \text { Class }_{S C}\right\} .
$$

The energy-demand analysis for a day $\{24-\mathrm{hour}\}$ is a one-hour resolution as a one-time slot, assuming that each hourly slot is 60 minutes. The shortest operational length of an appliance is assumed to be 1 minute. Accordingly, any appliance's operational length should be a multiple of 1 minute that extents from 1 minute to 60 minutes (one hour), or 1 minute to 120 minutes (two hours). Simultaneously, there are possibilities with an actual operational length, which is less than an hour, but in multiples of 1 minute. The proposed approach assumes that the appliance demand for this type of operational length exists for an entire hour and should schedule the appliance operation at an appropriate hourly time slot.

For an appliance $a$, the assumption is that the demand remains constant during its operation. When the rating of an appliance is $R_{a}$, the demand $D_{a}$ per its operational length $n_{a}$ is obtained using Eq. (3):

$$
D_{a}=\frac{R_{a}}{60} * n_{a} \mid \forall a \in\{A\} .
$$

\section{Entity_2-grid-tied rooftop $P V$ power information}

A grid-connected rooftop PV is assumed in this article, as a local source of uninterruptible renewable energy, to be available for appliance operation. $P V_{\text {day,gen }}$ is 
considered as the summation of $P V_{h, g e n}$, as shown in Eq. (4):

$$
P V_{\text {day,gen }}=\sum_{h=1}^{24} P V_{h, g e n} .
$$

Assuming the intermittent nature of PV, this paper considers the net-meter features to alleviate the uncertainty of rooftop PVs output power at the residence level. Furthermore, this paper also assumes that the PV installation capacity depends on the user's choice.

\section{Entity_3-day-ahead electricity tariff form utility}

However, this article assumes that a house's demand cannot be managed all alone with rooftop PV. Therefore, there is a seamless grid power every hour of the day $G P_{h}$. The day-ahead hourly tariff information $T_{h}$ from the utility for the grid power is shown in Eq. (5):

$$
\text { Tariff }=\left\{T_{1}, T_{2}, \cdots, T_{24}\right\} .
$$

The HEM utilizes suitable low-tariff hours of Eq. (5) to reduce EB.

\section{Entity_4-grid power constraint}

Operating appliances during low-tariff hours can cause demand peaks to be unsuitable for the grid. Thus, this study considers a constraint on power drawn from the grid to reduce such peaks. The assumption in this article is that the utility limits the user from drawing the grid power based on their rooftop PV installation capacity such that the grid power, drawn, should always be less than or equal to installed $P V_{\text {peak }}$, as listed in Eq. (6).

$$
G P_{h} \leq P V_{\text {peak }} \mid \forall h \in[1,2,3, \cdots, 24] .
$$

This consideration enables the utility to be sensitive to power requirement, given the intermittent nature of $\mathrm{PV}$, and it ensures grid power availability as a standby to avoid demand curtailment.

\section{Entity_5-hourly demand threshold constraint}

The assumption in this paper is that the demand threshold should be in a way that even if all nonshiftable appliances operate simultaneously during a particular time slot, they should not be curtailed. Furthermore, the demand threshold should be within grid power limits.

Hence, drawing upon Eq. (6), $D_{h, \text { threshold }}$ is assumed in Eq. (7):

$$
D_{h, \text { threshold }} \leq G P_{h} .
$$

The demand threshold is a limit set by the user on the appliance demand in a time slot, whereas the grid power is the hourly power available from the grid to the user. To distribute the demand uniformly throughout the day and to reduce demand peaks, Eqs. (6) and (7) attempt to limit users from drawing grid power and, in turn, encourage them to utilize renewable energy $(\mathrm{PV})$, thereby benefiting society concerning carbon footprints.

The utility decides whether the user can draw the grid power and communicates it to the HEM dayahead, which helps users keep the demand below a threshold, thereby preventing rebound peaks for grid stability. This threshold might delay or reduce the operation of specific appliances so as to prevent demand peaks, thereby discomforting users. Hence, the users can minimize this trade-off between personal comfort and grid reliability through proper PV installation, taking into account Eqs. (6) and (7).

\section{An algorithmic approach to generating cost-effective schedule pattern based on user preferences}

This section defines the user-preferred time window generator and schedule-pattern generation algorithms.

\subsection{User preferred time window}

A review of the literature illustrates that there is a possibility to generate a user-preferred time window using a classifier [24]. The classifier chooses the most preferred time slot by the user over some days and finally, considers it a user-preferred time slot; to be specific, a group of such user-preferred time slots produces a time window for an appliance.

For example, if a user operates an appliance, say an electric heater, for the first 20 days of the month at $5 \mathrm{am}$ and operates the same appliance during the last 10 days of the month at $6 \mathrm{am}$, then the classifier considers the user-preferred time slots for an electric heater as 5 am and 6 am, thereby generating a time window with time slots 5 am and 6 am considering 5 am as the full-comfort time slot. However, concerning the user preference within the last 10 days of the month, the full-comfort time slot should be 6 am because the users might change their preference for operating the appliance from the $5 \mathrm{am}$ time slot to $6 \mathrm{am}$. Thus, the classifier lacks generating the full-comfort time slots considering the recently preferred time slots by the user. In this regard, this article paper considers a time window generator based on the Artificial Neural Network (ANN) technique that generates the userpreferred time slots considering the recently used time slots to identify full-comfort time slots.

\subsubsection{An ANN technique for generating a time window}

The ANN network receives the input signals and then, multiplies it by the corresponding weights. A linear combiner output is generated by summing up all the weighted inputs, as shown in Eq. (8): 


$$
\text { Linear combiner output }=\sum_{i=1}^{n}\left[\text { input }_{i} * \text { weight }_{i}\right] \text {. }
$$

To generate the time window past 30 days of consumption, profiles containing the ON and OFF states of appliances at particular time slots are taken into consideration. The state of an appliance a, as shown in Eq. (9), at a particular time slot for a particular day is considered as inputs to the ANN:

$$
\text { App_state }_{T S, d}=\begin{aligned}
& 0 ; \quad \text { OFF state } \\
& 1 ; \quad \text { ON state }
\end{aligned}
$$

The weights of the ANN network are arbitrarily selected, as shown in Eq. (10):

$$
W_{d}=\frac{d}{100} \text {. }
$$

Therefore, considering the inputs from Eq. (9) and weights from Eq. (10), the weighted input of the ANN is shown in Eq. (11).

$$
\text { weighted_input } t_{T S, d}=A p p \_s t a t e_{T S, d} * W_{d} .
$$

Concerning Eqs. (8)-(11), the linear combiner output of ANN is shown in Eq. (12):

$$
\text { Linear combiner output }=\sum_{d=1}^{30}\left[\text { weighted_input }_{T S, d}\right] \text {. }
$$

If the linear combiner output at a particular time slot $T S$ is non-zero, then $T S$ is the preferred time slot by the user for appliance operation. On the other hand, if the output is zero, then $T S$ is considered as the nonpreferred time slot by the user for appliance operation. A particular time slot with the highest linear combiner output value is the time slot of highest priority, also known as a full-comfort time slot in this article.

\subsubsection{An algorithmic approach to generating a time window using the ANN technique}

The time window generator provides the flexibility to generate user-preferred time slots ahead of scheduling appliance operation considering Eqs. (8)-(12), as discussed in Algorithm 1.

The generated time window containing these preferred time slots is termed as the preferred time window for appliance $a$, as shown in Eq. (13), and discussed in Algorithm 1.

$$
P T W_{a}=\left\{T S_{1}, T S_{2}, \cdots, T S_{24}\right\} .
$$

An appliance gets operated with user ease during an appropriate time slot within this generated time window. For Class $_{N A}$ appliances, the time window contains a list of must-run time slots, whereas for Class $_{S A}$ appliances, it contains a range of optional operational time slots.

\subsection{Cost-effective schedule-pattern generation algorithms}

This section defines the pattern-generation algorithms considering entity_1, entity_2, entity_3, entity_4, entity_5 and generates the user-preferred time window. In this algorithmic approach, the assumption is that $G P_{h, a v a i}$ is initially equal to $G P_{h}$ and $P V_{h, a v a i}$ is equal to $P V_{h, g e n}$.

\subsubsection{The scheduling-pattern generation algorithm for Class $s_{N}$ appliances}

The demand $D_{a}$ is calculated using Eq. (3) for an appliance, $a \in \operatorname{Class}_{N A}$. However, it is assumed that $D_{a}$ is non-shiftable and remains constant for all time slots of $P T W_{a}$ defined by the user.

$\mathrm{Class}_{N A}$ appliances get scheduled for their operation in their respective defined time slots that belong to $P T W_{a}$, as discussed in Algorithm 2.

After generating the scheduling pattern for Class $_{N A}$, ClasssA appliances are arranged in order, priority-wise and class-wise (Class $S O$, Class $_{S T}$, and Class $_{S C}$ ), as discussed in Algorithm 3.

After sorting Class A $_{\text {a }}$ appliances, their scheduling pattern is generated, as per arranged order, one

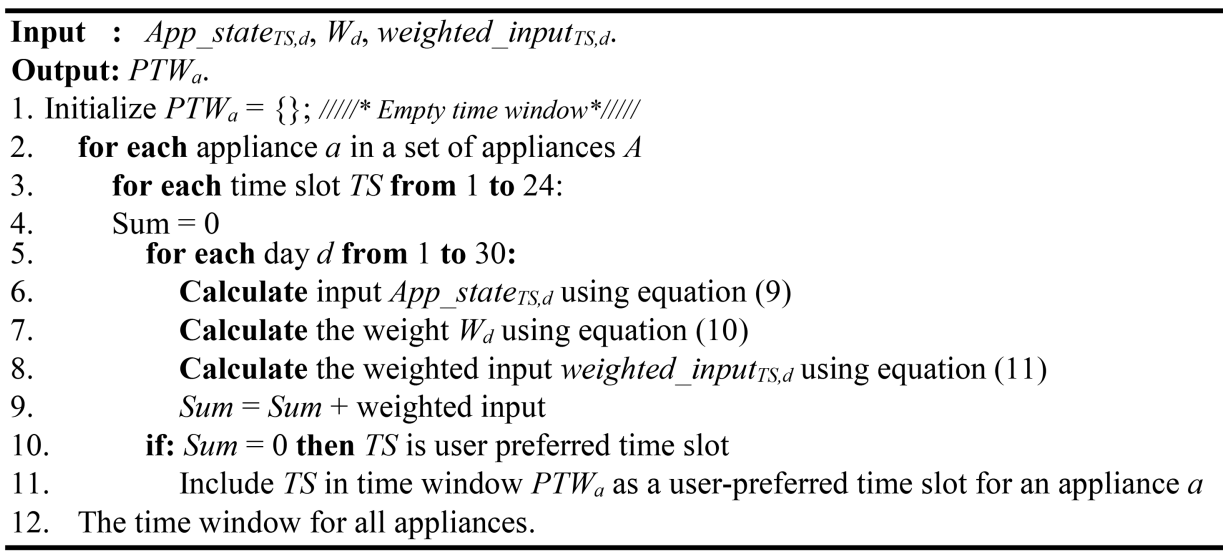

Algorithm 1: Time window generation algorithm. 


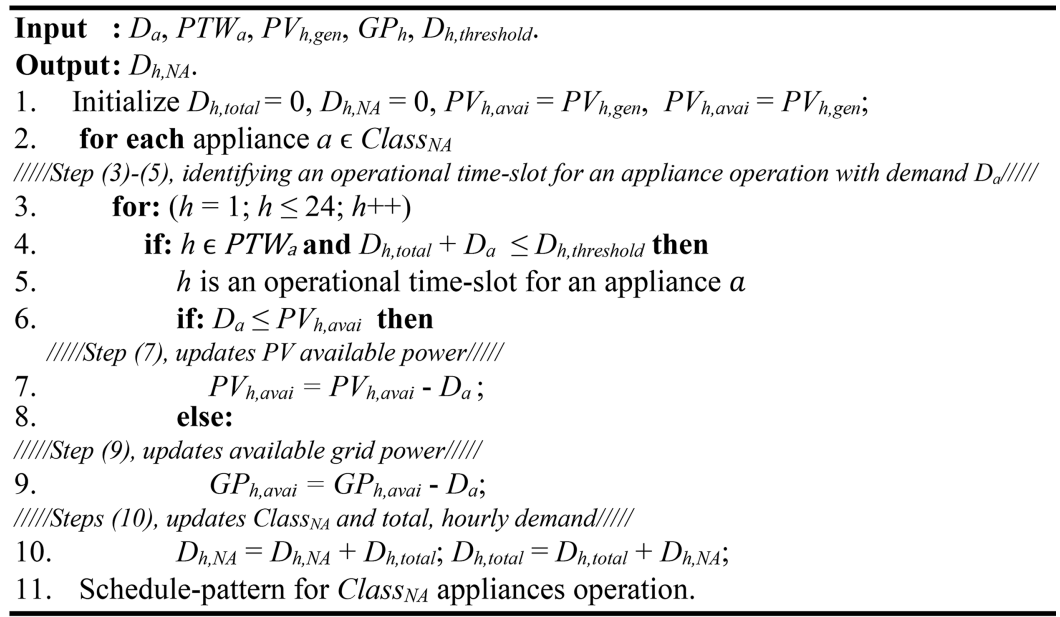

Algorithm 2: Class $_{N A}$ appliances scheduled pattern generation algorithm.

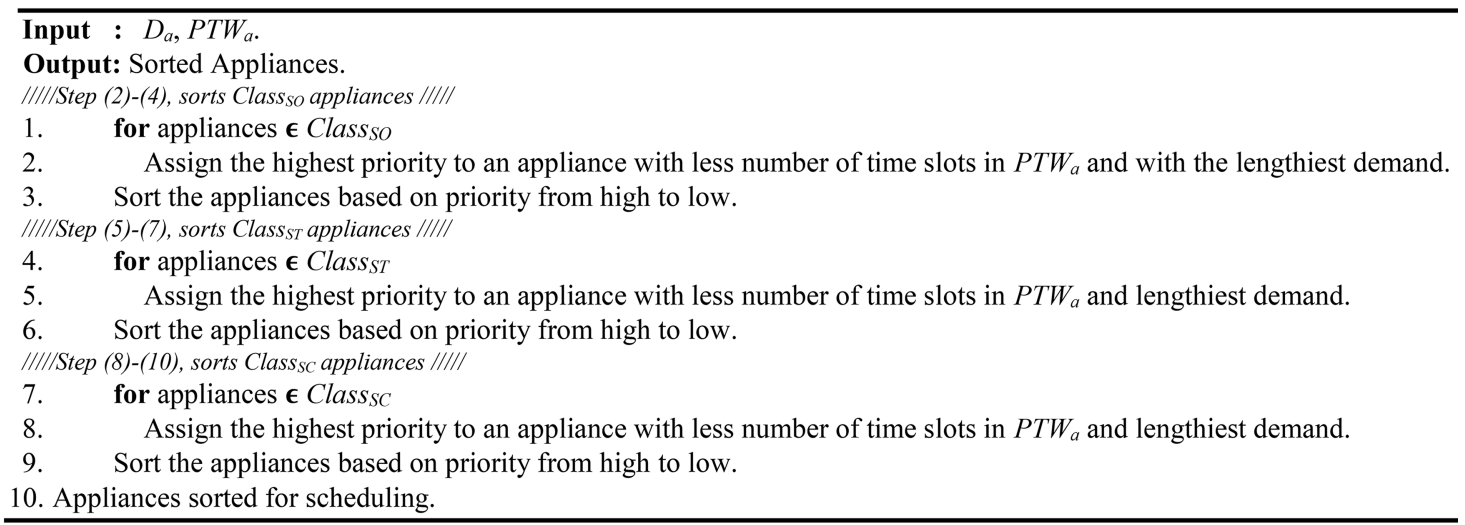

Algorithm 3: Class $_{S A}$ appliances sorting algorithm.

after the other sequentially as discussed below. The proposed scheduling pattern generation algorithms for shiftable appliances check all appropriate time slots with sufficient PV energy to meet the demand or low tariffs. Accordingly, they schedule the appliance operation at a suitable time slot with minimum tariff or maximum renewable energy utilization.

The PV appropriate hour is a suitable time slot within $P T W_{a}$ with minimum sufficient $P V$ power to accommodate the demand of an appliance a during its operation, as shown in Eq. (14):

$$
P V_{m n}=\min \left\{P V_{h, g e n} \mid h \in P T W_{a}\right\} .
$$

The idea behind the definition of $\mathrm{PV}$ appropriate time slots is to maximize the utilization of available renewable energy by accommodating the demand of an appliance within available energy in a specific time slot and allowing greater demands to use other higher energy time slots. The concept provides an opportunity to utilize renewable energy to its maximum and allows the end-user to maximize EB savings.

Similarly, the appropriate utility hour is a time slot within $P T W_{a}$, as shown in Eq. (15) and has minimum tariff and grid power, which is enough to meet the demand of an appliance during its operation.

$$
T_{m n}=\min \left\{T_{h} \mid h \in P T W_{a}\right\} .
$$

The scheduling pattern generation for non-shiftable appliances is the same, regardless of whether appliance operations are scheduled independently or simultaneously. Although simultaneous scheduling of shiftable appliances through optimization techniques helps reduce EB with user comforts, it may draw power from grids at the same time over low-tariff hours and sell $\mathrm{PV}$ power during high-tariff hours. The motivation behind the proposed scheme is to drive the end-user to utilize renewables for the benefits of the user, grid, and society. Accordingly, we proceeded with the scheduling pattern generation for shiftable appliances independently, thereby reducing $\mathrm{EB}$ with user comfort and drawing less power from the grid.

\subsubsection{The scheduling pattern generation algorithm for Class $_{S O}$ appliances}

For scheduling the operation of an appliance $a \in$ Class $S O$ operating once a day, the demand $D_{a}$ is 


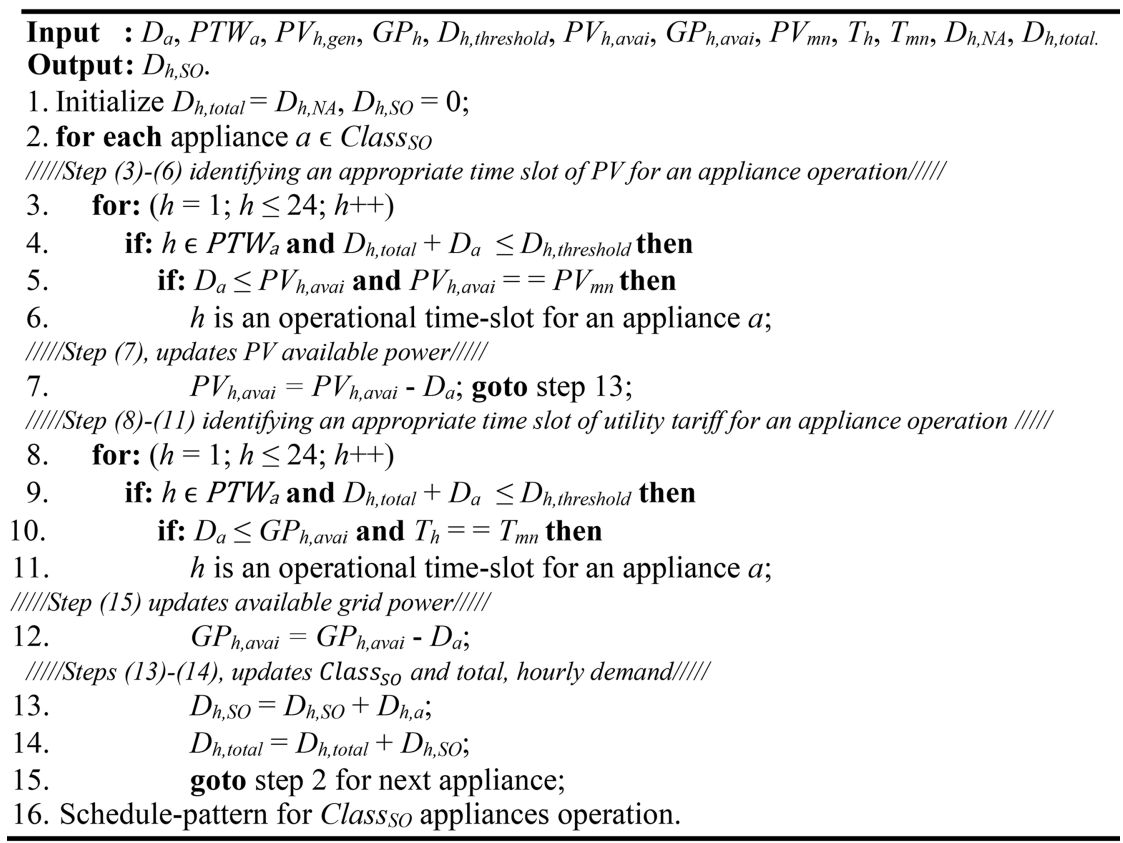

Algorithm 4: Class $_{S O}$ appliances scheduled pattern generation algorithm.

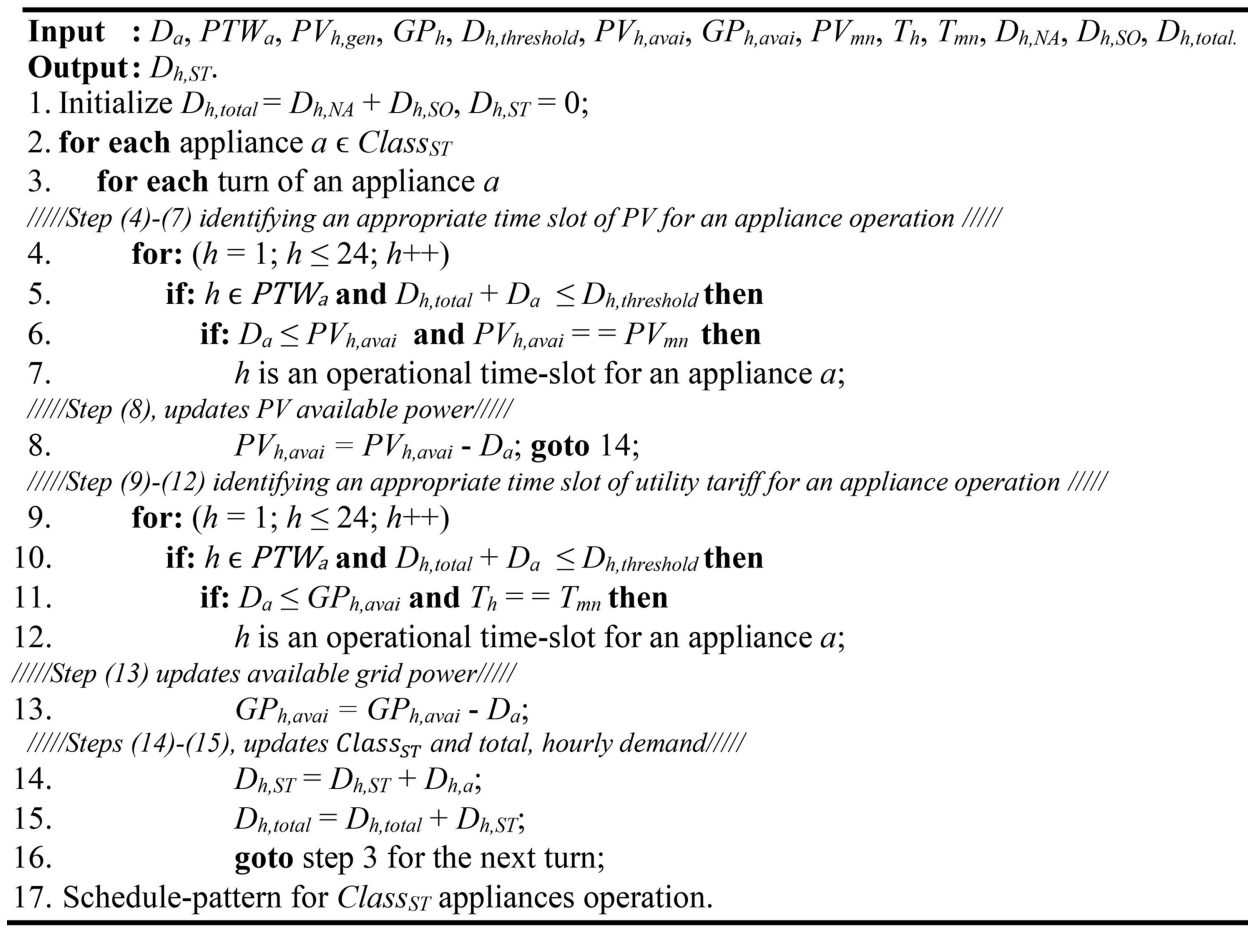

Algorithm 5: Class $_{S T}$ appliances scheduled pattern generation algorithm.

calculated using Eq. (3). Based on $D_{a}$, the pattern generation algorithm schedules appliance operation at an appropriate hour for $P V$ or utility, as represented in Eqs. (14) and (15).

Likewise, operations of Class $_{S O}$ appliances are scheduled subsequently with user preferences, as discussed in Algorithm 4.

After generating the scheduling pattern for
Classso appliances, that for Class generated (using Algorithm 5) concerning the updated, available $P V$ and grid power (from Algorithm 4).

\subsubsection{The scheduling pattern generation algorithm for Class $_{S T}$ appliances}

For scheduling the operation of an appliance $a \in$ Class $_{S T}$ operating twice a day, the demand $D_{a}$ is 
calculated using Eq. (3), assuming that this appliance operates two times a day at different time slots with the same operational length. Based on the demand $D_{a}$, the appliance gets scheduled for two turns of operation (first turn and second turn) subsequently in appropriate time slots, as discussed in Algorithm 5.

Likewise, the operations of $\mathrm{Class}_{S T}$ appliances are scheduled subsequently for each turn, as discussed in Algorithm 5.

After generating the scheduling pattern for Class $_{S T}$ appliances, that for Class $_{S C}$ appliances is generated (using Algorithm 6) concerning the updated, available $P V$, and grid power (from Algorithm 5).

\subsubsection{The schedule-pattern generation algorithm for Class $_{S C}$ appliances}

Appliances in this classification are non-preemptive in operation and their entire operation is scheduled as a whole during two suitable continuous time slots where there exists sufficient PV power or low tariffs. In cases of insufficient PV or low tariff for two consecutive time slots, the combination of suitable time slots of PV and grid should be preferred. For scheduling the operation of such appliance $a \in$ Class $_{S C}$ operating once a day for two continuous hours (between 60 and 120 minutes), demand $D_{a}$ is calculated using Eq. (3). Since the energy demand management is assumed to be using hourly time slots of 60 minutes, the demand $D_{a}$ of 120 minutes is segregated into demands $D_{a, 1}$ and $D_{a, 2}$ for the first 60 minutes and second 60 minutes of 120 minutes, respectively, as shown in Eq. (16):

$$
D_{a}=D_{a, 1}+D_{a, 2} \mid \forall a \in \operatorname{Class}_{S C}
$$

Based on the demands $D_{a, 1}$ and $D_{a, 2}$, appliance operation is scheduled at appropriate hours of $\mathrm{PV}$ or utility or combination of both, as discussed in Algorithm 6.

An assumption for such a class of appliance is that its operational length varies from more than 60 minutes to less than or equal to 120 minutes (i.e., $60<n_{a} \leq 120$ minutes). Based on a review of the literature, the operational length of most appliances does not exceed 120 minutes [25]. For example, the washing machine operates for 90 minutes, and since energy demand management in this article is hourly, 90 minutes are split into 60 minutes and 30 minutes. The demand within the two time frames of 60 and 30 minutes is calculated and then, the appliance operations are scheduled for two consecutive hourly time slots. Therefore, the authors assume that the demand of such an appliance exists for two continuous hours (between 0 and 120 minutes).

Likewise, operations of Class $_{S C}$ appliances are scheduled subsequently with user comfort, as discussed in Algorithm 6.
The HEM schemes defined via Algorithms 1-6 can be summarized as in a given set of multi-class appliances, past consumption data, demand threshold and grid-power draw constraint, and PV and utility information day-ahead. The algorithms find appropriate time slots to schedule appliances for nextday operations for cost-effective energy operation of appliances with comfort and constraint.

\section{Simulation results and discussions}

This section discusses simulation results using the proposed algorithms by assuming Class $_{N A}$ and Class $_{S A}$ appliances, as listed in Table 1 . Table 2 lists Class $_{N A}$ appliances and Tables 3, 4, and 5 list Class $_{S A}$ appliances with their operational length $n_{a}$ in minutes, generated preferred time window, and demand during operation. The assumption is that Tables 3,4 , and 5 list appliances as per priority, i.e., the appliance with a smaller time window and lengthiest demand at top of the list and vice versa using Algorithm 3.

The user defines the operational length of an appliance and the time window generator defines the preferred time slots for an appliance, respectively, as listed in Tables 2-5. For Class ${ }_{N A}$ appliances, the preferred time slots are must-run hours, whereas they are optional operating hours for Class $_{S A}$ appliances. The operational length defines the number of minutes that an appliance must run during its turn of operation.

For simplicity, each time slot is divided into 60 minutes and the minimum operational length of an appliance is 1 minute. Also, for the demonstration of the proposed approach, the assumption is that the PV capacity, demand threshold, and grid power limit values are $1.5 \mathrm{~kW}$ (peak), $1.5 \mathrm{kWh}$, and $1.5 \mathrm{kWh}$, respectively, resolving Eqs. (6) and (7). However, the $P V$ capacity, demand threshold, and grid power limit values may vary based on the user willingness, considering Eq. (6) and Eq. (7). This study assumes a dynamic electricity tariff in [26].

\subsection{Scheduling the operation of appliances using the proposed algorithmic approach}

The proposed algorithmic approach schedules the operation of Class $_{N A}$ appliances in their preferred time slots, as stated in Algorithm 2 and schedules the operation of Class $_{S A}$ appliances in appropriate time slots, as stated in Algorithms 4 to 6 .

\subsubsection{Scheduling Class ${ }_{N A}$ appliance operations}

For scheduling Class $_{N A}$ appliances, the demand $D_{a}$ for an appliance a is calculated using Eq. (3) and listed in Table 2. Using Algorithm 2, the operations of all theses Class $_{N A}$ appliances are scheduled sequentially in their respective, user-defined preferred time slots, as shown in Figure 2. 
Input : $D_{a}, P T W_{a}, P V_{h, \text { gen }}, G P_{h}, D_{h, \text { threshold, }} P V_{h, \text { avai }}, G P_{h, \text { avai }}, P V_{m n}, T_{h}, T_{m n}, D_{h, N A}, D_{h, S O}, D_{h, S T}, D_{h, \text { total }}$

Output: $D_{h, S C}$.

1. Initialize $D_{h, \text { total }}=D_{h, N A}+D_{h, S O}+D_{h, S T}, D_{h, S C}=0$;

2. for each appliance $a \in$ ClassSC $_{S}$

IIIIIStep (3)-(6) identifying an appropriate time slot of PV for an appliance operation IIIII

3. for: $(h=1 ; h \leq 24 ; h++)$ and if: $h, h+1 \in P T W_{a}$

4. if: Subroutine_a and Subroutine_b then

5. if: Subroutine $c$ and Subroutine $d$ then

6. $\quad$ if: $P V_{h, a v a i}==P V_{m n}$ then $h, h+l$ are consecutive operational time-slots for an appliance $a$; III/Step (7), updates PV available power/IIII

7. do Subroutine_1 and Subroutine_2; then goto step (34);

IIIIStep (9)-(12) identifying an appropriate time slot of PV for an appliance operation IIIII

8. for: $(h=1 ; h \leq 24 ; h++)$ and if: $h, h+1 \in P T W_{a}$

9. if: Subroutine $a$ and Subroutine_ $b$ then

10. if: Subroutine_c and Subroutine_d then

III/IStep (7), updates PV available power//III

11. if: $P V_{h+1, a v a i}==P V_{m n}$ then $h, h+1$ are consecutive operational time-slots for an appliance $a$;

12. do Subroutine 1 and Subroutine 2; then goto step (34);

IIIIStep (15)-(18) identifying an appropriate time slot of PV for an appliance operation IIIII

13. for: $(h=1 ; h \leq 24 ; h++)$ and if: $h, h+1 \in P T W_{a}$

14. if: Subroutine $a$ and Subroutine_b then

if: Subroutine_c and Subroutine_f then

if: $P V_{h, a v a i}=P V_{m n}$ then $h, h+1$ are consecutive operational time-slots for an appliance $a$;

16. if: $P V_{h, \text { avai }}==P V_{m n}$ then $h, h+I$ are
/II/Step (19), updates $P V$ and grid available power/I/I/

$17 . \quad$ do Subroutine 1 and Subroutine 4; then goto step (34);

IIII/Step (21)-(24) identifying an appropriate time slot of $\overline{P V}$ for an appliance operation /IIII

18. for: $(h=1 ; h \leq 24 ; h++)$ and if: $h, h+1 \in P T W_{a}$

19. if: Subroutine $a$ and Subroutine $b$ then

20. $\quad$ if: Subroutine $e$ and Subroutine $d$ then

21. if: $P V_{h+1, \text { avai }}==P V_{m n}$ then $h, \bar{h}+1$ are consecutive operational time-slots for an appliance $a$; IIIIStep (25), updates grid and PV available power/IIII

22. do Subroutine_3 and Subroutine_2; then goto step (34);

IIIIStep (27)-(30) identifying an appropriate time slot of utility tariff for an appliance operation IIIII

23. for: $(h=1 ; h \leq 24 ; h++)$ and if: $h, h+1 \in P T W_{a}$

24. if: Subroutine a and Subroutine_b then

25. if: Subroutine e and Subroutine $f$ then

26. if: $T_{h}==T_{m n}$ then $h, h+1$ are consecutive operational time-slots for an appliance $a$; I/I/Itep (31), updates grid available power//III

27. do Subroutine_3 and Subroutine_4; then goto step (34);

III/Step (33)-(36) identifying an appropriate time slot of utility tariff for an appliance operation IIIII

28. for: $(h=1 ; h \leq 24 ; h++)$ and if: $h, h+1 \in P T W_{a}$

29. if: Subroutine $a$ and Subroutine $b$ then

30. if: Subroutine_e and Subroutine $f$ then

31. if: $T_{h+1}==T_{m n}$ then $h, h+1$ are consecutive operational time-slots for an appliance $a$;

III/IStep (31), updates grid available power/IIII

32. do Subroutine_3 and Subroutine_4; then goto step (34);

33. if: operation of an appliance $a$ is scheduled then

III/ISteps (40)-(43), updates Class $S_{S C}$ and total, hourly demand//III

34. $\quad D_{h, \text { Class }_{S C}}=D_{h, \text { Class }_{S C}}+D_{a, 1}$;

35. $D_{h+1, \text { Class }_{S C}}=D_{h+1, \text { Class }_{S C}}+D_{a, 2}$

36. $D_{h, \text { total }}=D_{h, \text { total }}+D_{h, \text { Class }}$;

37. $D_{h+1, \text { total }}=D_{h+1, \text { total }}+D_{h+1, \text { Class }_{S C}}$;

38. Schedule-pattern for $\operatorname{Class}_{S C}$ appliances operation.

Subroutine a: $D_{h, \text { total }}+D_{a, 1} \leq D_{h, \text { threshold }}$;

Subroutine_b: $D_{h+1, \text { total }}+D_{a, 2} \leq D_{h, \text { threshold }}$;

Subroutine_c: $D_{a, 1} \leq P V_{h, \text { avai }}$;

Subroutine_d: $D_{a, 2} \leq P V_{h+1, \text { avai }}$;

Subroutine_e: $D_{a, 1} \leq G P_{h, \text { avai }}$;

Subroutine f: $D_{a, 2} \leq G P_{h+1, \text { avai }}$;

Subroutine 1: $P V_{h, \text { avai }}=P V_{h, \text { avai }}-D_{a, 1}$;

Subroutine_2: $P V_{h+1, \text { avai }}=P V_{h+1, \text { avai }}-D_{a, 2}$;

Subroutine_3: $G P_{h, \text { avai }}=G P_{h, \text { avai }}-D_{a, 1}$;

Subroutine_4: $G P_{h+1, a v a i}=G P_{h+1, a v a i}-D_{a, 2}$;

Algorithm 6: Class $_{S C}$ appliances scheduled pattern generation algorithm. 
Table 1. List of appliances with their rating for 1 bedroom-hall-kitchen home classified as Class $_{N A}$ and Class $_{S A}$, further sub-classified as Class $_{S O}$, Class $_{S T}$, and Class $_{S C}$.

\begin{tabular}{|c|c|c|c|c|c|c|}
\hline \multirow{2}{*}{ Room } & \multirow{2}{*}{ Appliance } & \multirow{2}{*}{ Rating } & \multirow{2}{*}{ Class $_{N A}$} & \multicolumn{3}{|c|}{ Class $_{S A}$} \\
\hline & & & & Class $_{S O}$ & Class $_{S T}$ & Class $_{S C}$ \\
\hline \multirow{3}{*}{ Bed room } & CFL_1 & $0.018 \mathrm{kWh}$ & $\checkmark$ & & & \\
\hline & Tube_1 & $0.036 \mathrm{kWh}$ & $\checkmark$ & & & \\
\hline & Fan_1 & $0.5 \mathrm{kWh}$ & $\checkmark$ & & & \\
\hline \multirow{6}{*}{ Living room } & CFL_2 & $0.018 \mathrm{kWh}$ & $\checkmark$ & & & \\
\hline & Tube_2 & $0.036 \mathrm{kWh}$ & $\checkmark$ & & & \\
\hline & Fan_2 & $0.5 \mathrm{kWh}$ & $\checkmark$ & & & \\
\hline & TV & $0.1 \mathrm{kWh}$ & $\checkmark$ & & & \\
\hline & Iron & $1.1 \mathrm{kWh}$ & & $\checkmark$ & & \\
\hline & Vacuum cleaner & $1.3 \mathrm{kWh}$ & & $\checkmark$ & & \\
\hline \multirow{5}{*}{ Kitchen } & Tube_3 & $0.036 \mathrm{kWh}$ & $\checkmark$ & & & \\
\hline & Refrigerator & $0.15 \mathrm{kWh}$ & $\checkmark$ & & & \\
\hline & Kettle & $1.5 \mathrm{kWh}$ & & $\checkmark$ & & \\
\hline & Rice cooker & $1.3 \mathrm{kWh}$ & & & $\checkmark$ & \\
\hline & Electric stove & $0.9 \mathrm{kWh}$ & & & $\checkmark$ & \\
\hline \multirow{3}{*}{ Bath room } & Water heater & $1.5 \mathrm{kWh}$ & & $\checkmark$ & & \\
\hline & Well pump & $0.9 \mathrm{kWh}$ & & $\checkmark$ & & \\
\hline & Washing machine & $2 \mathrm{~kW}^{*}$ & & & & $\checkmark$ \\
\hline
\end{tabular}

*: Rated maximum power during their term of operation; $\checkmark$ : Represents that an appliance belongs to a particular class.

Table 2. Class $_{N A}$ appliances with their respective operational length, preferred time slots, and demand per hour.

\begin{tabular}{|c|c|c|c|}
\hline Class $_{N A}$ & $\begin{array}{c}n_{a} \text { per hour } \\
\text { (mins) }\end{array}$ & $\begin{array}{c}P T W_{a} \\
\text { (hours) }\end{array}$ & $\begin{array}{c}D_{a} \text { per hour } \\
(\mathrm{kWh})\end{array}$ \\
\hline CFL_1 & 60 & $1 \sim 6,23 \sim 24$ & 0.018 \\
\hline Tube_1 & 60 & $19 \sim 21$ & 0.036 \\
\hline Fan_1 & 60 & $1 \sim 6,19 \sim 24$ & 0.5 \\
\hline $\mathrm{CFL}_{2} 2$ & 60 & $1 \sim 6,22 \sim 24$ & 0.018 \\
\hline Tube_2 & 60 & $7 \sim 8,18 \sim 21$ & 0.036 \\
\hline Fan_2 & 60 & $7 \sim 21$ & 0.5 \\
\hline TV & 60 & $17 \sim 21$ & 0.1 \\
\hline Tube_3 & 60 & $6 \sim 7,18 \sim 20$ & 0.036 \\
\hline Refrigerator & 60 & $1 \sim 24$ & 0.15 \\
\hline
\end{tabular}

Table 3. Class $S O$ appliances with their respective operational length, preferred time slots, and demand per turn.

\begin{tabular}{llccc}
\hline Class $_{S A}$ & $\begin{array}{c}\boldsymbol{n}_{\boldsymbol{a}} \text { during each } \\
\text { turn of operation } \\
\text { (mins) }\end{array}$ & $\begin{array}{c}\boldsymbol{P} \boldsymbol{T} \boldsymbol{W}_{\boldsymbol{a}} \\
\text { (hours) }\end{array}$ & $\begin{array}{c}\boldsymbol{D}_{\boldsymbol{a}} \text { during its } \\
\text { turn of operation } \\
\text { (kWh) }\end{array}$ \\
\hline \multirow{2}{*}{ Class $_{S O}$ Kettle } & 20 & $7 \sim 8$ & 0.5 \\
& Iron & 15 & $7 \sim 8$ & 0.275 \\
& Water heater & 10 & $5 \sim 6$ & 0.25 \\
& Vacuum cleaner & 30 & $6 \sim 10$ & 0.65 \\
& Well pump & 30 & $4 \sim 10$ & 0.45 \\
\hline
\end{tabular}


Table 4. Class $_{S T}$ appliances with their respective operational length, preferred time slots, and demand per turn.

\begin{tabular}{|c|c|c|c|c|c|}
\hline \multirow{2}{*}{\multicolumn{2}{|c|}{ Class $_{S A}$}} & \multirow{2}{*}{$\begin{array}{c}n_{a} \text { during each } \\
\text { turn of operation } \\
\text { (mins) }\end{array}$} & \multicolumn{2}{|c|}{$P T W_{a}$ (hours) } & \multirow{2}{*}{$\begin{array}{c}D_{a} \text { during its } \\
\text { turn of operation } \\
(\mathrm{kWh}) \\
\end{array}$} \\
\hline & & & $\begin{array}{c}\text { 1st } \\
\text { turn }\end{array}$ & $\begin{array}{l}2 n d \\
\text { turn }\end{array}$ & \\
\hline \multirow{2}{*}{ Class $_{S T}$} & Rice cooker & 30 & $6 \sim 9$ & $15 \sim 17$ & 0.65 \\
\hline & Electric stove & 25 & $6 \sim 9$ & $14 \sim 16$ & 0.375 \\
\hline
\end{tabular}

Table 5. Class $_{S C}$ appliances with their respective operational length, preferred time slots, and demand per turn per hour.

\begin{tabular}{clcccc}
\hline \multicolumn{1}{c}{ Class $_{S C}$} & $\begin{array}{c}\text { Time slots } \\
\text { (hours) }\end{array}$ & $\begin{array}{c}\boldsymbol{n}_{\boldsymbol{a}} \text { during the } \\
\text { turn of operation } \\
\text { (mins) }\end{array}$ & $\begin{array}{c}\boldsymbol{D}_{\boldsymbol{a}} \text { during the } \\
\text { turn of operation } \\
\text { (kWh) }\end{array}$ & $\begin{array}{c}\boldsymbol{P} \boldsymbol{T}_{\boldsymbol{a}} \\
\text { (hours) }\end{array}$ \\
\hline \multirow{2}{*}{ Washing machine } & First-time slot & 60 & 0.779 & $D_{a, 1}$ & $5 \sim 12$ \\
& Second-time slot & 30 & 0.138 & $D_{a, 2}$ & \\
\hline
\end{tabular}

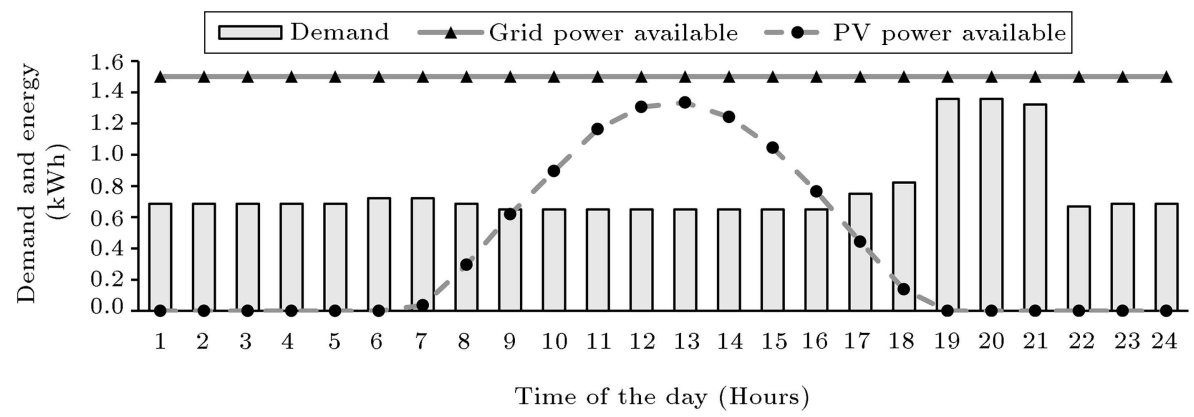

Figure 2. Class $_{N A}$ appliances scheduled pattern using Algorithm 1.

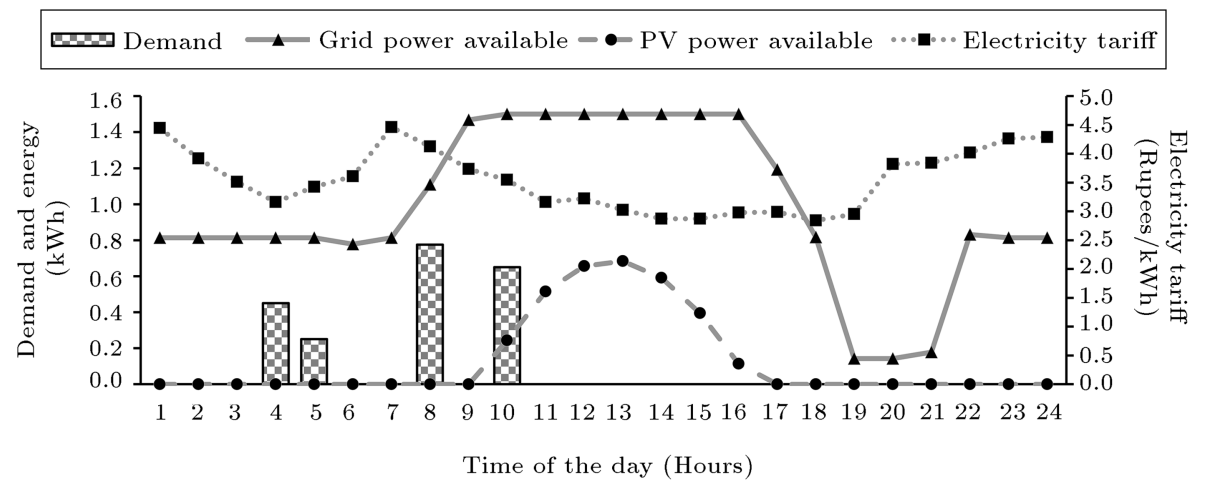

Figure 3. Class $_{S O}$ appliances scheduled pattern using Algorithm 3.

\subsubsection{Scheduling operations of Class $s_{S A}$ appliances}

For scheduling the operations of Class $_{S A}$ appliances, the demand $D_{a}$ is calculated using Eq. (3) for each appliance $a \in$ Class $_{S A}$ and tabulated in Tables 35. Algorithms 4-6 scheduled the operations of all these Class $_{S A}$ appliances at their respective appropriate hours of either PV or utility, respectively, as shown in Figures 3-5.

As discussed in the proposed approach, the appliances listed in Tables 2-5 are scheduled as per user preference, as shown in Figure 6.

\subsection{Demonstration of the effectiveness of the proposed HEM scheme}

The HEM approach proposed in this article is an analytical method to minimize EB with an hourly demand threshold including user comfort.

\subsubsection{Demonstrating the effectiveness of ANN-based time window generation technique}

We considered full-comfort-based time slots for demonstrating the effectiveness of the time window generator. Full-comfort time slots are those with highest priority from the generated time window. We have compared 


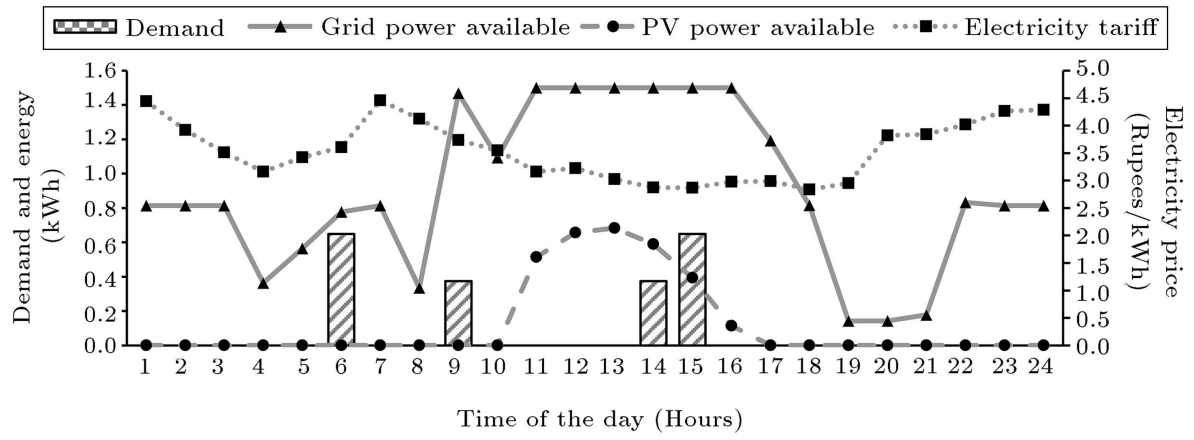

Figure 4. Class $_{S T}$ appliances scheduled pattern using Algorithm 4.

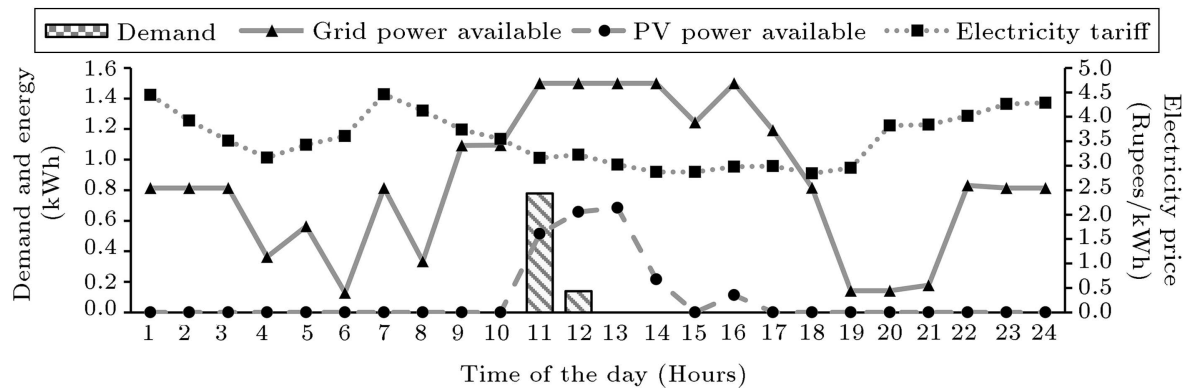

Figure 5. Class $_{S C}$ appliances scheduled pattern using Algorithm 5.

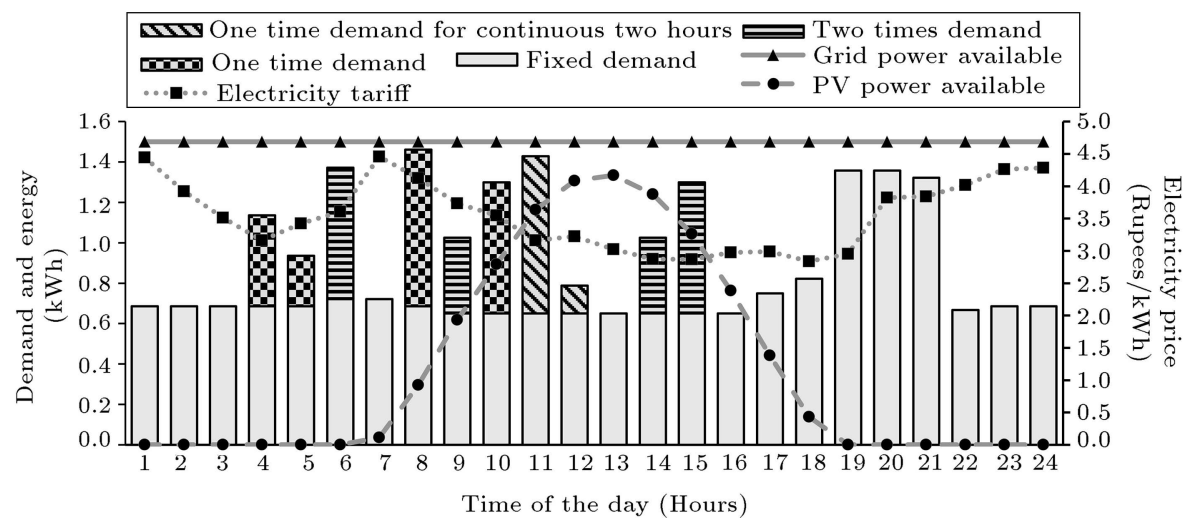

Figure 6. Multi-class appliances scheduled pattern with user comfort.

the proposed ANN-based generated full-comfort time slots with a classifier-based generated full-comfort time slots, as listed in Table 6.

In a full-comfort scenario, the user operates appliances with $100 \%$ comfort and no operational delay calculated using Eqs. (17) and (18):

$$
\begin{aligned}
\text { Operational delay }= & \mid(\text { Comfortable hour }) \\
& -(\text { Scheduled hour }) \mid,
\end{aligned}
$$

$$
\begin{aligned}
\text { Percentage of comfort }= & \frac{(24-\text { Operational delay })}{24} \\
& * 100 .
\end{aligned}
$$

The observation made based on the comparison is that there is an operational delay of 0 to 4 hours with a comfort ranging between $83.33 \%$ and $100 \%$ for the classifier-based full-comfort time slots concerning ANN-based full-comfort time slots. This discomfort is because the classifier considers the most preferred time slot as a user-preferred time slot, and ANN considers the recently used time slots over some recent days as user-preferred time slots. However, comfort should always be $100 \%$ with no operational delay in terms of full comfort. In this regard, the ANN-based time window generation technique overrules the classifierbased time window generation technique.

\subsubsection{Demonstrating the effectiveness of the proposed cost-effective scheduling pattern generation algorithms}

We considered the operation scheduling for appliances with a full-comfort scenario and a cost-effective sce- 
Table 6. Outcomes of Class $_{S A}$ appliances in terms of operational delay and percentage of comfort concerning the full-comfort time slots identified by ANN and Naïve Bayes classifier.

\begin{tabular}{|c|c|c|c|c|c|c|c|c|c|c|c|}
\hline \multirow[b]{3}{*}{ Parameters } & \multicolumn{10}{|c|}{ Class $_{S A}$ appliances } & \\
\hline & \multirow{2}{*}{ Kettle } & \multirow{2}{*}{ Iron } & \multirow{2}{*}{$\begin{array}{l}\text { Water } \\
\text { heater }\end{array}$} & \multirow{2}{*}{$\begin{array}{l}\text { Vacuum } \\
\text { cleaner }\end{array}$} & \multirow{2}{*}{$\begin{array}{l}\text { Well } \\
\text { pump }\end{array}$} & \multicolumn{2}{|c|}{$\begin{array}{c}\text { Rice } \\
\text { cooker }\end{array}$} & \multicolumn{2}{|c|}{$\begin{array}{c}\text { Electric } \\
\text { stove }\end{array}$} & \multicolumn{2}{|c|}{$\begin{array}{l}\text { Washing } \\
\text { machine }\end{array}$} \\
\hline & & & & & & $\begin{array}{c}\text { 1st } \\
\text { turn }\end{array}$ & $\begin{array}{c}\text { 2nd } \\
\text { turn }\end{array}$ & $\begin{array}{c}\text { 1st } \\
\text { turn }\end{array}$ & $\begin{array}{c}\text { 2nd } \\
\text { turn }\end{array}$ & $\begin{array}{c}\text { 1st } \\
\text { turn }\end{array}$ & $\begin{array}{l}\text { 2nd } \\
\text { turn }\end{array}$ \\
\hline Full-comfort & 7 & 8 & 6 & 10 & 10 & 8 & 17 & 9 & 16 & 9 & 10 \\
\hline time slot (hour) Naïve Bayes & 8 & 7 & 5 & 7 & 6 & 8 & 16 & 8 & 16 & 11 & 12 \\
\hline Operational delay (hours) & 1 & 1 & 1 & 3 & 4 & 0 & 1 & 1 & 0 & 2 & 2 \\
\hline Percentage of comfort (\%) & 95.83 & 95.83 & 95.83 & 87.5 & 83.33 & 100 & 95.83 & 95.83 & 100 & 91.67 & 91.67 \\
\hline
\end{tabular}

Table 7. Assessed parameters for full-comfort and cost-effective based scheduling appliances operations.

\begin{tabular}{lccc}
\hline \multirow{2}{*}{\multicolumn{1}{c}{ Parameters }} & \multicolumn{3}{c}{ Approach } \\
\cline { 2 - 3 } & \multicolumn{2}{c}{ Full-comfort } & \multirow{2}{*}{ CEF } \\
\cline { 2 - 3 } & ANN & Nä̈ve Bayes \\
\hline Total demand (kWh) & 23.50 & 23.50 & 23.50 \\
Total PV generated (kWh) & 9.28 & 9.28 & 9.28 \\
Total PV used (kWh) & 6.44 & 6.85 & 7.75 \\
Total grid power draw (kWh) & 17.06 & 16.66 & 15.76 \\
Total buy bill (Rupees) & 63.25 & 62.19 & 57.98 \\
Total sell bill (Rupees) & 8.63 & 7.43 & 4.69 \\
Total electricity bill (Rupees) & 54.62 & 54.76 & 53.28 \\
Peak demand (kWh) & 1.88 & 2.21 & 1.46 \\
Overall average comfort (\%) & 100.00 & 93.94 & 93.18 \\
$\mathrm{CO}_{2}$ emission (kg) & 7.65 & 7.47 & 7.06 \\
\hline
\end{tabular}

nario for demonstrating the effectiveness of the proposed scheduling pattern generation algorithms. In a full-comfort scenario, the user prefers full-comfort time slots only to schedule the operation of appliances with $100 \%$ comfort and no constraints. In the cost-effective scenario, the user prefers to schedule appliances with a certain comfort level considering constraints.

Figure 7 presents these scenarios with emphasis on the operational demand of scheduled appliances in full-comfort time slots generated by the classifier and ANN technique and the cost-effective scheduling pattern generated using time window by the scheduling pattern generation algorithms. The presented scenarios were assessed for a day in terms of different parameters, as listed in Table 7, calculated using Eqs. (19)-(28).

$$
\text { Total demand }=\sum_{h=1}^{24}\left(D_{h, N A}+D_{h, S A}\right)
$$

where $D_{h, S A}=D_{h, S O}+D_{h, S T}+D_{h, S C}$.

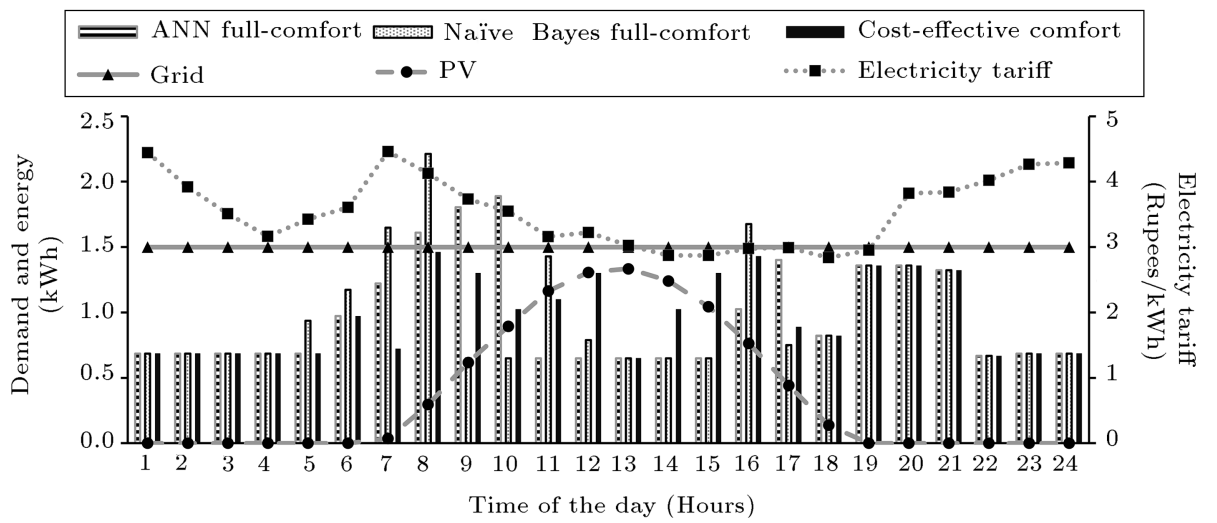

Figure 7. ANN full-comfort, Naïve Bayes full-comfort, and cost-effective comfort based scheduled pattern of multi-class appliances. 
Total $P V$ generated $=\sum_{h=1}^{24} P V_{h, \text { gen }}$,

Total $P V$ power used $=\sum_{h=1}^{24}\left(P V_{h}-P V_{h, \text { avai }}\right)$,

Total grid power drawn $=\sum_{h=1}^{24}\left(G P_{h}-G P_{h, a v a i}\right)$,

Total electricity buy bill

$$
=\sum_{h=1}^{24}\left[\left(G P_{h}-G P_{h, \text { avai }}\right) * T_{h}\right],
$$

Total electricity sell bill $=\sum_{h=1}^{24}\left[\left(P V_{h, \text { avai }}\right) * T_{h}\right]$,

Total electricity bill $=$ Total buy bill - Total sell bill,

Peak demand $=\max ($ demand of the day $)$,

Overall average comfort $=$ average

(percentage of comfort of allshiftable appliances),

$\mathrm{CO}_{2}$ emission $=$ Total grid power drawn $* k$,

where $k=0.4483$ (calculated from carbonfund.org)

Table 7 shows that compared to the ANNbased full-comfort scenario, cost-effective scheduling increases $P V$ utilization from $6.44 \mathrm{kWh}$ to $7.75 \mathrm{kWh}$. This increment in $P V$ utilization reduces power drawn from the grid from $17.06 \mathrm{kWh}$ to $15.76 \mathrm{kWh}$. Furthermore, it minimizes the total electricity net bill from 54.32 rupees to 53.28 rupees. Moreover, Table 7 illustrates that cost-effective scheduling reduces the peak demand from $1.88 \mathrm{kWh}$ to $1.46 \mathrm{kWh}$. The reduction in net $\mathrm{EB}$ while preserving user preferences considering constraints was achieved with the average overall comfort of $93.18 \%$, as listed in Table 7 . The decrease in the power drawn from the fossil fuel-based grid benefits the user and grid, and the society concerning carbon footprints as the cost-effective scheduling reduced carbon emission from $7.65 \mathrm{~kg}$ to $7.06 \mathrm{~kg}$, as listed in Table 7.

The benefits listed and highlighted in Table 7 are achieved because PTW allocates a certain degree of freedom to scheduling the operation of appliances at appropriate hours (PV available hours or lowtariff hours), and the threshold on hourly demand limits the peaks. Therefore, the inference from these results is that $\mathrm{EB}$ reduction is possible with a certain degree of comfort and constraints while preserving user preferences.

\section{Conclusion}

This study proposed a heuristic approach to costeffective energy management without compromising user comforts while considering constraints via scheduling appliances operations for a home with multi-class appliances. An ANN-based time window, termed as a user-preferred time window (PTW) concept, was applied to achieve comfort. A threshold on hourly demand was also considered in this approach to prevent rebound peaks at low-tariff hours. The proposed approach addresses the trade-off between Electricity Bill (EB) and comfort by scheduling appliances upon taking into account user preferences, day-ahead tariff, gridpower draw and hourly demand threshold constraints, and rooftop PV.

This study compared the proposed ANN-based generated full-comfort time slots with classifier-based generated full-comfort time slots and found that the ANN-based time window generation technique overruled the classifier-based time window generation technique. The scheduling of appliance operations with a full-comfort scenario and a cost-effective scenario was considered to demonstrate the effectiveness of the proposed scheduling pattern generation algorithms. The inference from the obtained simulation results through cost-effective scheduling was that EB could be reduced through increment in PV utilization, including reducing demand peaks and $\mathrm{CO}_{2}$ emission with maximum possible comfort. Therefore, the proposed approach was of benefit to both (a) the user by reducing EB and (b) the grid by reducing demand peaks while still preserving user comfort. These benefits were achieved because PTW allocated a certain degree of freedom for scheduling appliances at appropriate hours (PV available hours or low-tariff hours), and the threshold on hourly demand limited the peaks. Therefore, it was found that the reduction in EB was possible with a certain degree of comfort. It can be concluded the proposed heuristic approach is a feasible choice for multi-class appliance scheduling for cost-effective energy demand management with user ease.

\section{Nomenclature}

$\begin{array}{ll}a & \text { Appliance } \\ A & \text { Set of appliances } \\ \text { App_state }_{T S, d} & \text { State of an appliance } a \text { at a } \\ & \text { particular time slot } T S \text { of the day } d \\ \text { CEF } & \text { Cost-effective } \\ \text { Class }_{N A} & \text { Non-shiftable appliances }\end{array}$




\begin{tabular}{|c|c|}
\hline Class $_{S A}$ & Shiftable appliances \\
\hline Class $_{S C}$ & $\begin{array}{l}\text { One time in a day for two continuous } \\
\text { hours when shiftable appliances are } \\
\text { operating }\end{array}$ \\
\hline Class $_{S O}$ & $\begin{array}{l}\text { One time in a day when shiftable } \\
\text { appliances operated }\end{array}$ \\
\hline Class $_{S T}$ & $\begin{array}{l}\text { Two times a day when shiftable } \\
\text { appliances operated }\end{array}$ \\
\hline $\mathrm{COM}$ & Comfort \\
\hline$d$ & Day $[1,2,3, \cdots, 30]$ \\
\hline$D_{a}$ & Demand of an appliance (kWh) \\
\hline$D_{a, 1}$ & $\begin{array}{l}\text { Demand of an appliance during the } \\
\text { first } 60 \text { minutes of two continuous } \\
\text { hours of operation (kWh) }\end{array}$ \\
\hline$D_{a, 2}$ & $\begin{array}{l}\text { Demand of an appliance during the } \\
\text { second } 60 \text { minutes of two continuous } \\
\text { hours of operation }(\mathrm{kWh})\end{array}$ \\
\hline$D_{h, a}$ & $\begin{array}{l}\text { Demand of an appliance during an } \\
\text { hour }(\mathrm{kWh})\end{array}$ \\
\hline$D_{h, S A}$ & $\begin{array}{l}\text { Total demand of } \text { Class }_{S A} \text { appliances } \\
\text { during an hour } h\end{array}$ \\
\hline$D_{h, S C}$ & $\begin{array}{l}\text { Total demand of ClassSO appliances } \\
\text { during an hour } h\end{array}$ \\
\hline$D_{h, S O}$ & $\begin{array}{l}\text { Total demand of Class } S \text { appliances } \\
\text { during an hour } h\end{array}$ \\
\hline$D_{h, \mathrm{ST}}$ & $\begin{array}{l}\text { Total demand of } \text { Class }_{S T} \text { appliances } \\
\text { during an hour } h\end{array}$ \\
\hline$D_{h, \text { threshold }}$ & Threshold on hourly demand (kWh) \\
\hline$D_{h, \text { total }}$ & Total hourly demand (kWh) \\
\hline$G P_{h}$ & $\begin{array}{l}\text { Grid power during an hour of the day } \\
(\mathrm{kWh})\end{array}$ \\
\hline$G P_{h, a v a i}$ & Hourly available grid power $(\mathrm{kWh})$ \\
\hline$n_{a}$ & $\begin{array}{l}\text { Operational length of an appliance } \\
\text { (minutes) }\end{array}$ \\
\hline$O p D$ & Operational delay (hours) \\
\hline $\mathrm{PoC}$ & Percentage of comfort (\%) \\
\hline$P T W_{a}$ & $\begin{array}{l}\text { Preferred time window for an } \\
\text { appliance operation with time slots } \\
T S_{1}, T S_{2}, \cdots, T S_{24}\end{array}$ \\
\hline$P V_{d a y, g e n}$ & PV power generated for the day (kWh) \\
\hline $\mathrm{PV}_{h, a v a i}$ & Hourly available PV power (kWh) \\
\hline $\mathrm{PV}_{h, g e n}$ & PV power generated hourly (kWh) \\
\hline$P V_{m n}$ & Minimum PV power (kWh) \\
\hline$P V_{\text {peak }}$ & Peak power of PV (kWp) \\
\hline$R_{a}$ & Rating of an appliance (kWh) \\
\hline$T_{h}$ & Hourly electricity tariff (Rupees/kWh) \\
\hline$T_{m n}$ & $\begin{array}{l}\text { Minimum electricity tariff } \\
\text { (Rupees/kWh) }\end{array}$ \\
\hline$T S$ & Time slot $[1,2,3, \cdots, 24]$ \\
\hline
\end{tabular}

$W_{d}$

weighted_

input $_{T S, d}$
Corresponding weight for a state of an appliance $a$ at a particular time slot $T S$ of the day $d$

Weighted input for a state of an appliance $a$ at a particular time slot $T S$ of the day $d$.

\section{References}

1. Majid, M.S., Rahman, H.A., Hassan, M.Y., et al. "Demand side management using direct load control for residential", 2006 4th Student Conference on Research and Development, Selangor, pp. 241-245 (2006).

2. Perez-Lombard, L., Ortiz, J., and Pout, C. "A review on buildings energy consumption information", Energy and Buildings, 40(3), pp. 394-398 (2008).

3. Khajavi, P., Monsef, H., and Abniki, H. "Load profile reformation through demand response programs using smart grid", 2010 Modern Electric Power Systems, Wroclaw, pp. 1-6 (2010).

4. Mohsenian-Rad, A., Wong, V.W.S., Jatskevich, J., et al. "Autonomous demand-side management based on game theoretic energy consumption scheduling for the future smart grid", IEEE Transaction on Smart Grid, 1(3), pp. 320-331 (2010).

5. Mohsenian-Rad, A.H. and Leon-Garcia, A. "Optimal residential load control with price prediction in realtime electricity pricing environments", IEEE Transaction on Smart Grid, 1(2), pp. 120-133 (2010).

6. Conejo, A.J., Morales, J.M., and Baringo, L. "Realtime demand response model", IEEE Transactions on Smart Grid, 1(3), pp. 236-242 (2010).

7. Kimand, T.T. and Poor, H.V. "Scheduling power consumption with price uncertainty", IEEE Transaction on Smart Grid, 2, pp. 519-527 (2011).

8. Xiong, G., Chen, C., Kishore, S., et al. "Smart (inhome) power scheduling for demand response on the smart grid", Proc. IEEE Conference on Innovative Smart Grid Technologies (ISGT), Anaheim, CA, USA, pp. 1-7 (2012).

9. Loenthiran, T., Srinivasan, D., and Shun, T.Z. "Demand side management in smart grid using heuristic optimization", IEEE Transaction on Smart Grid, 3, pp. 1244-1252 (2012).

10. Chen, Z., Wu, L., and Fu, Y. "Real-time pricebased demand response management for residential appliances via stochastic optimization and robust optimization", IEEE Transaction on Smart Grid, 3, pp. 1822-1831 (2012).

11. Chen, X., Wei, T., and Hu, S. "Uncertainty-aware household appliance scheduling considering dynamic electricity pricing in smart home", IEEE Transactions on Smart Grid, 4(2), pp. 932-941 (2013).

12. Zhao, Z., Lee, W.C., Shin, Y., et al. "An optimal power scheduling method for demand response in home energy management system", IEEE Transactions on Smart Grid, 4(3), pp. 1391-1400 (2013). 
13. Agnetis, A., Pascale, G., Detti, P., et al. "Load scheduling for household energy consumption optimization", IEEE Transactions on Smart Grid, 4(4), pp. 2364-2373 (2013).

14. Liu, Y., Yuen, C., Huang, S., et al. "Peak-to-average ratio constrained demand-side management with consumer's preference in residential smart grid", IEEE Journal of Selected Topics in Signal Processing, 8, pp. 1084-1097 (2014).

15. Roh, H.T. and Lee, J.W. "Residential demand response scheduling with multi-class appliances in the smart grid", IEEE Transaction on Smart Grid, 7, pp. 94-104 (2016).

16. Pipattanasomporn, M., Kuzlu, M., and Rahman, S. "An algorithm for intelligent home energy management and demand response analysis", IEEE Transactions on Smart Grid, 3(4), pp. 2166-2173 (2012).

17. Jo, H., Kim, S., and Joo, S. "Smart heating and air conditioning scheduling method incorporating customer convenience for home energy management system", IEEE Transactions on Consumer Electronics, 59(2), pp. 316-322 (2013).

18. Ogwumike, C., Short, M., and Abugchem, F. "Heuristic optimization of consumer electricity costs using a generic cost model", Energies, 9, p. 6 (2015).

19. Althaher, S., Mancarella, P., and Mutale, J. "Automated demand response from home energy management system under dynamic pricing and power and comfort constraints", IEEE Transactions on Smart Grid, 6(4), pp. 1874-1883 (2015).

20. Ma, K., Yao, T., Yang, J., et al. "Residential power scheduling for demand response in smart grid", International Journal of Electrical Power \& Energy Systems, 78, pp. 320-325 (2016).

21. Safdarian, A., Fotuhi-Firuzabad, M., and Lehtonen M. "Optimal residential load management in smart grids: A decentralized framework", IEEE Transactions on Smart Grid, 7(4), pp. 1836-45 (2016).

22. Pilloni, V., Floris, A., Meloni, A., et al. "Smart home energy management including renewable sources: a qoe-driven approach", IEEE Transactions on Smart Grid, 9(3), pp. 2006-2018 (2018).
23. Ganesh Kumar, C. and Premanand V.C. "Demand response management system with discrete time window using supervised learning algorithm", Cognitive Systems Research, 57, pp. 131-138 (2019).

24. Javaid, N., Ahmed, F., Ullah, I., et al. "Towards cost and comfort based hybrid optimization for residential load scheduling in a smart grid", Energies, 10, p. 1546 (2017).

25. Dong, M., Meira, P.C.M., Xu, W., et al. "An event window based load monitoring technique for smart meters", IEEE Transactions on Smart Grid, 3(2), pp. $787-796$ (2012).

26. Indian Energy Exchange "Day ahead market, area prices, S2", [Online], Available at: https://www. iexindia.com/marketdata/areaprice.aspx.

\section{Biographies}

Mir Firdouse Ali Khan received his BSc of Technology in Electronics and Communication Engineering from Shaaz College of Engineering and Technology in 2007 and MSc of Technology in Embedded Systems from Auroras Technological and Research Institute in 2010. He is currently pursuing his $\mathrm{PhD}$ degree from the Department of Electrical Engineering, Anna University, India. His current research interests include embedded systems and home energy demand management.

Premanand Venkatesh Chandramani received his BSc degree in Electrical and Electronics Engineering from Annamalai University in 1995, MSc degree in Electrical Engineering from UNC Charlotte in 1999, $\mathrm{PhD}$ degree in Electrical and Computer Engineering from the University of Delaware in 2004. He is currently a Professor at the Department of Electronics and Communication Engineering at Sri Sivasubramaniya Nadar College of Engineering, India. He has published more than 40 articles in both refereed journals and conferences. His research interests include radiation study on radio frequency microelectronics and demand response in microgrids. 